\title{
Differential Increase in Natriuretic Peptides in Elite Dynamic and Static Athletes
}

\author{
Haruhiko Date, MD; Takuroh Imamura, MD; Hisamitsu Onitsuka, MD; \\ Masakazu Maeno, MD; Reiko Watanabe, MD; Kensaku Nishihira, MD; \\ Takeshi Matsuo, MD; Tanenao Eto, MD
}

\begin{abstract}
The echocardiographic measures and plasma concentrations of either atrial natriuretic peptide (ANP) or brain natriuretic peptide (BNP) were compared in elite judo practitioners (static athletes), elite marathon runners (dynamic athletes) and healthy controls to investigate the relationship between the different types of left ventricular (LV) hypertrophy and plasma concentrations of natriuretic peptides in athletes. The LV mass and LV wall thickness of marathon runners and judo practitioners were significantly greater than those of controls. The LV end-diastolic dimension index was significantly larger in the marathon group, but smaller in the judo group. The left atrial dimension (LAD) index was significantly larger only in marathon runners. Plasma BNP concentrations were higher in both the judo and marathon groups than in controls, and positively correlated with LV mass as well as with deceleration time. Plasma ANP concentrations were significantly higher in marathon runners than in the controls and judo groups, and positively correlated with the LAD index, but negatively correlated with ejection fraction. Multivariate analyses showed that the type of athlete and LAD index were independent predictors of plasma BNP and ANP concentrations, respectively. Thus, there is an intimate link between plasma concentrations of natriuretic peptides and cardiac morphology in different types of athletes. (Circ J 2003; 67: 691-696)
\end{abstract}

Key Words: Athlete's heart; Atrial natriuretic peptide; Brain natriuretic peptide

$\Delta^{n}$

increase in left ventricular (LV) chamber size, wall thickness and mass as a result of athletic training are generally described as 'athlete's heart'! Mitchell et al classified individual sports as dynamic or static depending on the level of intensity of the exercise and according to these criteria, judo is classified as high staticlow dynamic, whereas marathon running is considered low static-high dynamic? The athletes in these classifications have distinct types of LV hypertrophy: dynamic athletes have eccentric hypertrophy whereas static athletes develop concentric hypertrophy.

Atrial natriuretic peptide (ANP) is a cardiac hormone that is secreted from the atria and has diuretic, natriuretic, and vasodilator actions 3,4 Brain natriuretic peptide (BNP) is secreted mainly from the ventricles and although it has striking similarity to ANP with respect to amino acid sequence and pharmacological spectrum, they are derived from distinct genes. $\mathrm{A}$ growing body of evidence has demonstrated that in various heart diseases, the plasma concentrations of ANP and BNP are increased ${ }^{6-9}$ and the latter is a useful marker of diagnosis and prognosis! ${ }^{10-12}$ The LV geometry affects the plasma concentrations of ANP and BNP in patients with essential hypertension? but the relationship between cardiac hypertrophy and plasma natriuretic peptides in athletes remains unknown. We investigated the plasma concentrations of ANP and BNP in dynamic and static athletes. We used echocardiography to also evaluate

(Received February 12, 2003; revised manuscript received May 19, 2003; accepted May 22, 2003)

First Department of Internal Medicine, Miyazaki Medical College, Miyazaki, Japan

Mailing address: Takuroh Imamura, MD, First Department of Internal Medicine, Miyazaki Medical College, 5200 Kihara, Kiyotake, Miyazaki 889-1692, Japan. E-mail: imatak@ post.miyazaki-med.ac.jp the effects of different types of sports on cardiac morphology and function. The aim of this study was to elucidate the relationship between plasma natriuretic peptides and either cardiac morphology or function in the different types of athletes.

\section{Methods}

Subjects

Written informed consent to participate in the study was obtained from 20 elite marathon runners ( $26.8 \pm 8.5$ years), 15 elite judo practitioners ( $24.7 \pm 2.6$ years) and 16 controls ( $26.2 \pm 1.7$ years). All participants were male and none were taking any form of medication or special nutritional supplements such as protein powder. The dietary patterns of the judo practitioners and marathon runners were essentially the same. The duration of their athletic commitment was $20.1 \pm$ 10.0 years for the marathon runners and $16.5 \pm 3.9$ years for the judo practitioners. The former run more than $20 \mathrm{~km}$ and latter practice for $2 \mathrm{~h}$, every day of the week. Controls were age-matched, healthy physicians who had not recently trained or been involved in high performance sport.

\section{Echocardiographic Recording}

Echocardiographic examination was performed using a phased array, ultrasound system (Sonos 5500, Philips Medical System, USA) with a 2.5-MHz transducer. Echocardiograms were evaluated according to the recommendations of the American Society of Echocardiography $!^{3}$ Left atrial dimension (LAD) at end-systole was measured at the maximal dimension from the leading edge of the posterior wall of the aorta to the dominant line representing the posterior wall of the LA. Interventricular septal (IVS) diastolic thickness, LV posterior wall diastolic thickness, and 
Table 1 Baseline Characteristics of the 2 Types of Athletes and the Controls

\begin{tabular}{lccc}
\hline \hline & Dynamic athletes $(n=20)$ & Static athletes $(n=15)$ & Controls $(n=16)$ \\
\hline Age $($ years $)$ & $26.8 \pm 8.5$ & $24.7 \pm 2.6$ & $26.2 \pm 1.7$ \\
BW $(\mathrm{kg})$ & $53.4 \pm 12.2^{2 * 11}$ & $107.7 \pm 21.1^{\dagger}$ & $62.1 \pm 5.7$ \\
BMI $\left(\mathrm{kg} / \mathrm{m}^{2}\right)$ & $18.2 \pm 8.5^{\dagger 11}$ & $34.1 \pm 6.0^{\dagger}$ & $21.4 \pm 1.66$ \\
$\mathrm{MBP}(\mathrm{mmHg})$ & $89.3 \pm 1.7^{\dagger 11}$ & $100.5 \pm 2.4$ & $97.5 \pm 1.7$ \\
HR (beats $/ \mathrm{min})$ & $56.0 \pm 8.56^{\dagger \S}$ & $65.9 \pm 7.54$ & $70.1 \pm 7.74$ \\
\hline
\end{tabular}

${ }^{*} p<0.05$ vs controls; ${ }^{\dagger} p<0.01$ vs controls; ${ }^{+} p<0.001$ vs controls; ${ }^{{ }^{*}} p<0.01$ vs static athletes; $" p<0.001$ vs static athletes.

Values are means $\pm S D$.

$B M I$, boby mass index; $B W$, body weight; HR, heart rate; $M B P$, mean blood pressure.

Table 2 Echocardiographic Measures and Resting Natriuretic Peptide Concentrations in the 2 Types of Atheletes and the Controls

\begin{tabular}{lccc}
\hline \hline & Dynamic athletes $(n=20)$ & Static athletes $(n=15)$ & Controls $(n=16)$ \\
\hline LAD index $\left(\mathrm{mm} / \mathrm{m}^{2}\right)$ & $22.4 \pm 2.03^{* \dagger}$ & $17.3 \pm 2.19$ & $18.5 \pm 1.77$ \\
LVD index $\left(\mathrm{mm} / \mathrm{m}^{2}\right)$ & $31.2 \pm 2.11^{* \dagger}$ & $22.7 \pm 2.95^{*}$ & $26.9 \pm 2.26$ \\
LVWT $(\mathrm{mm})$ & $21.9 \pm 1.9^{* \dagger}$ & $25.5 \pm 3.5^{*}$ & $16.2 \pm 2.72$ \\
LV mass $(\mathrm{g})$ & $318.3 \pm 48.0^{\text {q\# }}$ & $496.2 \pm 114.8^{\pi}$ & $189.7 \pm 36.0$ \\
EF $(\%)$ & $62.3 \pm 8.05$ & $64.9 \pm 8.12$ & $65.9 \pm 0.3$ \\
E/A ratio & $2.13 \pm 0.556$ & $1.93 \pm 0.55$ & $1.91 \pm 0.45$ \\
DT $(\mathrm{ms})$ & $176 \pm 33.0$ & $199 \pm 33.9$ & $182 \pm 30.5$ \\
MSWS $\left(\mathrm{kdynes} / \mathrm{cm}^{2}\right)$ & $164.1 \pm 34.3$ & $158.8 \pm 31.5$ & $169.1 \pm 39.1$ \\
ANP $(\mathrm{pg} / \mathrm{ml})$ & $11.48 \pm 5.80^{\ddagger}$ & $5.44 \pm 5.38$ & $5.33 \pm 1.86$ \\
BNP $(\mathrm{pg} / \mathrm{ml})$ & $6.91 \pm 6.85^{\|}$ & $8.16 \pm 3.66^{\pi}$ & $2.59 \pm 3.04$ \\
\hline
\end{tabular}

" $p<0.05$ vs controls; ${ }^{*} p<0.001$ vs controls; ${ }^{\star} p<0.0005$ vs controls; ${ }^{\|} p<0.0001$ vs controls; ${ }^{s} p<0.005$ vs static athletes; ${ }^{\dagger} p<0.001$ vs static athletes; ${ }^{\#} p<0.0001$ vs static athletes.

Values are means $\pm S D$.

$D T$, deceleration time; E/A ratio, ratio of $E$ wave to A wave; $E F$, ejection fraction; $L A D$ index, left atrial dimension index $\left(L A D / m^{2}\right)$; $L V D$ index, left ventricular end-diastolic dimension index $\left(L V D / m^{2}\right) ; L V$ mass, left ventricular mass; $L V W T$, left ventricular wall thickness, (= interventricular septal diastolic thickness + left ventricular posterior wall diastolic thickness); MSWS. meridional systolic wall stress.

LV diastolic dimension (LVD) were measured from the LV short-axis view at the papillary muscle tip level using 2dimensionally guided M-mode echocardiography. Three consecutive cardiac cycles were measured and averaged. Images were recorded on a 0.5 -inch S-VHS video tape recorder. The LV mass was calculated using the Penn-cube formula described by Devereux and Reichek ${ }^{14}$ as follows:

LV mass $=1.04(($ IVS diastolic thickness + LVD + LV posterior wall thickness) $\left.{ }^{3}-\mathrm{LVD}^{3}\right)-13.6 \mathrm{~g}$.

The values of LAD and LVD were then adjusted for body surface area to generate the index values. The $\mathrm{LV}$ wall thickness was defined as IVS diastolic thickness + LV posterior wall diastolic thickness. LV ejection fraction (LVEF) was obtained using a modified Simpson method based on the American Society of Echocardiography recommendation 15 Pulse Doppler echocardiography measured mitral inflow velocity in the apical 4-chamber view with the sampling volume placed at the tip of the mitral valve. The diastolic parameters of peak mitral flow velocity of the early rapid filling wave (E), peak velocity of the late filling wave due to atrial contraction (A), the E/A ratio and deceleration time of the $\mathrm{E}$ wave were then measured. The value for meridional systolic wall stress was calculated using Grossman's equation ${ }^{16}$ and is defined as follows:

$$
\sigma \mathrm{m}=\mathrm{PRi} / 2 \mathrm{H}(1+\mathrm{H} / 2 \mathrm{Ri}) \text {, }
$$

where $\sigma \mathrm{m}$ is meridional systolic wall stress, $\mathrm{P}$ is systolic $\mathrm{LV}$ pressure, $\mathrm{Ri}$ is the inner radius and $\mathrm{H}$ is the systolic wall thickness of the LV. Because this was a non-invasive study, we substituted systolic blood pressure for systolic LV pressure.

\section{Assays of ANP and BNP}

Venous blood samples were obtained from the athletes in the late morning before lunch and at least $12 \mathrm{~h}$ after the last training session. Plasma concentrations of ANP were measured using a specific immunoradiometric assay (Shiono RIA ANP assay kit, Shionogi Co, Ltd) as reported!7 This assay sandwiches $\alpha$-human ANP between 2 monoclonal antibodies, one against its carboxy-terminal sequence and the other against its ring structure, and plasma extraction is not required. Plasma concentrations of BNP were measured using a highly sensitive immunoradiometric assay (Shiono RIA BNP assay kit, Shionogi Co) as reported!8 This assay sandwiches human BNP between one monoclonal antibody that recognizes its carboxy-terminal and another that recognizes its ring structure. Plasma extraction is not necessary. Cross-reactivity of ANP with BNP was less than $0.001 \%$ on a molar basis.

\section{Statistics}

All statistical comparisons were performed using the Statistical Package Stat View-J 4.5 (Abacus Concepts Inc, Calabasus, CA, USA). Data are expressed as means \pm SD. Unpaired two-tailed $\mathrm{t}$-tests examined differences among the marathon runners, judo practitioners and controls. The relationship between plasma natriuretic peptides and predictor variables was explored by univariate analysis followed by stepwise multivariate regression analyses. Plasma concentrations of ANP or BNP constituted dependent variables in our model. Age, body weight, body mass, mean blood pressure, heart rate, LAD index, LVD index, LV wall thickness, LV mass, LVEF, E/A ratio, deceleration time, meridional systolic wall stress and type of athlete 
Table 3 Univariate and Multivariate Analysis for Predicting Plasma Concentration of ANP

\begin{tabular}{|c|c|c|c|c|}
\hline \multirow{2}{*}{ Variable } & \multicolumn{2}{|c|}{ Univariate analysis } & \multicolumn{2}{|c|}{ Multivariate analysis } \\
\hline & Coefficient & $p$ value & Coefficient & $p$ value \\
\hline LAD index $\left(\mathrm{mm} / \mathrm{m}^{2}\right)$ & 0.442 & 0.0015 & 0.54 & 0.0199 \\
\hline Age (years) & 0.437 & 0.0017 & 0.379 & 0.0013 \\
\hline$E F(\%)$ & -0.403 & 0.0041 & -0.227 & 0.0112 \\
\hline LVD index $\left(\mathrm{mm} / \mathrm{m}^{2}\right)$ & 0.386 & 0.0062 & & \\
\hline$B M I\left(\mathrm{~kg} / \mathrm{m}^{2}\right)$ & -0.386 & 0.0062 & & \\
\hline$B W(\mathrm{~kg})$ & -0.378 & 0.0074 & & \\
\hline HR (beats/min) & -0.279 & 0.0522 & & \\
\hline$M B P(m m H g)$ & -0.246 & 0.0887 & & \\
\hline LVWT (mm) & 0.106 & 0.4684 & & \\
\hline$L V$ mass $(g)$ & -0.049 & 0.7382 & & \\
\hline MSWS (kdynes/cm²) & 0.021 & 0.8842 & & \\
\hline Type of athlete & 0.019 & 0.8994 & & \\
\hline E/A ratio & -0.004 & 0.9758 & & \\
\hline$D T(m s)$ & 0.0005 & 0.9974 & & \\
\hline
\end{tabular}

$B M I$, body mass index; $B W$, body weight; DT, deceleration time; E/A ratio, ratio of $E$ wave to A wave; EF, ejection fraction; HR, heart rate; $L A D$, left atrial dimension; $L V D$ index, left ventricular end-diastolic dimension index; LV mass, left ventricular mass; $L V W T$, left ventricular wall thickness; MBP, mean blood pressure; MSWS, meridional systolic wall stress.

Table 4 Univariate and Multivariate Analysis for Predicting Plasma Concentration of BNP

\begin{tabular}{|c|c|c|c|c|}
\hline \multirow{2}{*}{ Variable } & \multicolumn{2}{|c|}{ Univariate analysis } & \multicolumn{2}{|c|}{ Multivariate analysis } \\
\hline & Coefficient & $p$ value & Coefficient & $p$ value \\
\hline Age (years) & 0.636 & $<0.0001$ & 0.685 & $<0.0001$ \\
\hline Type of athlete & 0.418 & 0.0028 & 0.487 & $<0.0001$ \\
\hline LV mass $(g)$ & 0.401 & 0.0043 & & \\
\hline$L V W T(\mathrm{~mm})$ & 0.38 & 0.0071 & & \\
\hline$D T(m s)$ & 0.285 & 0.047 & & \\
\hline E/A ratio & -0.265 & 0.0662 & & \\
\hline$B W(k g)$ & 0.238 & 0.0991 & & \\
\hline$B M I\left(\mathrm{~kg} / \mathrm{m}^{2}\right)$ & 0.219 & 0.1306 & & \\
\hline$E F(\%)$ & -0.201 & 0.1654 & & \\
\hline$M B P(m m H g)$ & 0.16 & 0.2707 & & \\
\hline LAD index $\left(\mathrm{mm} / \mathrm{m}^{2}\right)$ & 0.127 & 0.385 & & \\
\hline LVD index $\left(\mathrm{mm} / \mathrm{m}^{2}\right)$ & -0.104 & 0.4764 & & \\
\hline MSWS (kdynes $\left./ \mathrm{cm}^{2}\right)$ & -0.076 & 0.6035 & & \\
\hline HR (beats/min) & -0.056 & 0.7036 & & \\
\hline
\end{tabular}

$B M I$, body mass index; $B W$, body weight; DT, deceleration time; $E / A$ ratio, ratio of $E$ wave to A wave; EF, ejection fraction; $H R$, heart rate; LAD, left atrial dimension; $L V D$ index, left ventricular end-diastolic dimension index; LV mass, left ventricular mass; $L V W T$, left ventricular wall thickness; MBP, mean blood pressure; MSWS, meridional systolic wall stress.

(dynamic or static) represented independent variables. Relationships between continuous variables were determined by linear regression analysis. Differences were considered significant at $\mathrm{p}$-values below 0.05 .

\section{Results}

\section{Characteristics of the 3 Exercise Groups}

The baseline characteristics of the athletes and controls are summarized in Table 1. Age did not significantly differ among the 3 groups. The values for body weight and body mass index were smaller in the marathon runners than in the judo practitioners and controls. Mean blood pressure was also lower in the marathon group than in the judo and control groups. The marathon group had lower heart rates than the judo and control groups.

\section{Echocardiographic Findings}

Echocardiographic findings are summarized in Table 2. The value of the LAD index was significantly larger in the marathon group than in either the judo or the control group. The LVD index was significantly larger in the marathon group and smaller in the judo group compared with the control group. LV wall thickness and LV mass were significantly larger in both athlete groups than in the controls. Systolic function (LVEF), diastolic function (E/A ratio and deceleration time) and meridional systolic wall stress did not differ among the 3 groups.

\section{Plasma Concentrations of ANP and BNP}

Plasma ANP concentrations were significantly higher in marathon runners $(11.48 \pm 5.80 \mathrm{pg} / \mathrm{ml})$ than in the control $(5.33 \pm 1.86 \mathrm{pg} / \mathrm{ml})$ or judo group $(5.44 \pm 5.38 \mathrm{pg} / \mathrm{ml})$ (marathon vs control, $\mathrm{p}<0.0005$; marathon vs judo, $\mathrm{p}<0.005$ ), whereas plasma BNP concentrations were higher in both the judo $(8.16 \pm 3.66 \mathrm{pg} / \mathrm{ml})$ and marathon groups $(6.91 \pm$ $6.85 \mathrm{pg} / \mathrm{ml})$ compared with controls $(2.59 \pm 3.04 \mathrm{pg} / \mathrm{ml})$ (judo vs control, $\mathrm{p}<0.0001$; marathon vs control, $\mathrm{p}<0.05$ ) (Table 2). Tables 3 and 4 show the results of univariate and multivariate analyses that evaluated the factors contributing to plasma ANP and BNP concentrations, respectively. Univariate analysis showed that LAD index, age, LVEF, LVD index, body mass index and body weight correlated with plasma ANP concentrations. Among these variables, LAD index, age and LVEF were independent predictors of the plasma concentration of ANP (Table 3), as revealed by 

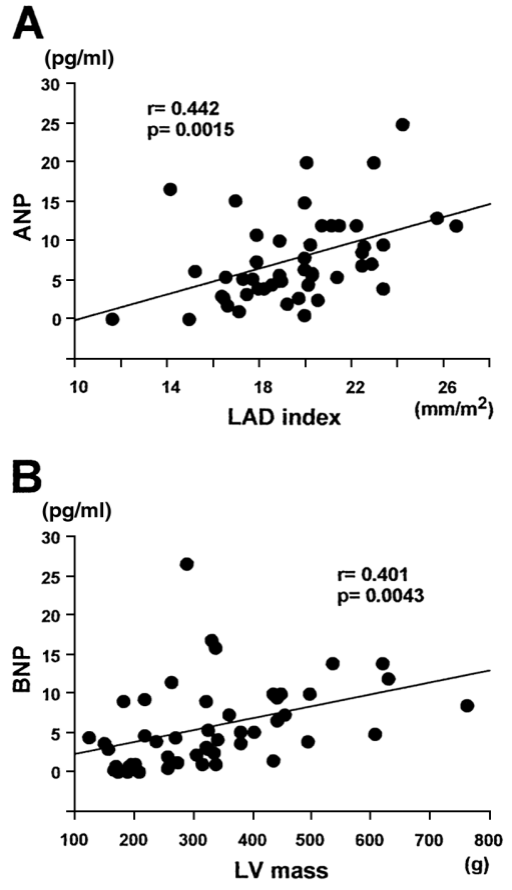

Fig 1. Correlation between atrial natriuretic peptide (ANP) and left atrial dimension (LAD) index (A) and between brain natriuretic peptide (BNP) and left ventricular (LV) mass (B) in all study participants. Plasma ANP concentrations positively correlate with LAD index $(\mathrm{r}=0.442, \mathrm{p}=0.0015)(\mathrm{A})$ and plasma $\mathrm{BNP}$ concentrations positively correlate with LV mass $(\mathrm{r}=0.401, \mathrm{p}=0.0043)(\mathrm{B})$.

stepwise multivariate analysis. Univariate analysis correlated age, type of athlete, LV mass, LV wall thickness and deceleration time with plasma BNP concentrations. Age and type of athlete were significant determinants of plasma BNP concentrations (Table4). Linear regression analysis revealed a significant relationship between plasma ANP concentrations and LAD index $(r=0.442, p=0.0015)$ and between plasma BNP concentrations and LV mass $(r=0.401$, $\mathrm{p}=0.0043$ ) (Fig 1). In addition, ANP concentrations negatively correlated with LVEF $(r=-0.403$, $p=0.0041)$, whereas BNP concentrations positively correlated with deceleration time ( $\mathrm{r}=0.285, \mathrm{p}=0.047)$ (Fig 2) and also tended to correlate with the E/A ratio $(\mathrm{r}=-0.265, \mathrm{p}=0.0662)$.

\section{Discussion}

The principal finding of the present study is that plasma BNP concentrations were high in both static and dynamic athletes, whereas plasma ANP concentrations were high only in dynamic athletes. Plasma BNP positively correlated with LV mass and LV wall thickness, but not with LVD index or LAD index. In contrast, plasma ANP positively correlated with LAD index and LVD index, but not with LV mass or LV wall thickness. The type of athlete was a significant determinant of BNP, but not of ANP concentrations, whereas the LAD index was a significant determinant of ANP concentrations. Plasma ANP concentrations negatively correlated with LV systolic function, whereas plasma BNP concentrations positively correlated with $\mathrm{LV}$ diastolic function in these study groups.

Multivariate analysis suggested that the type of athlete might affect the plasma BNP concentrations via a mechanism(s) other than that of cardiac morphology. Regardless,
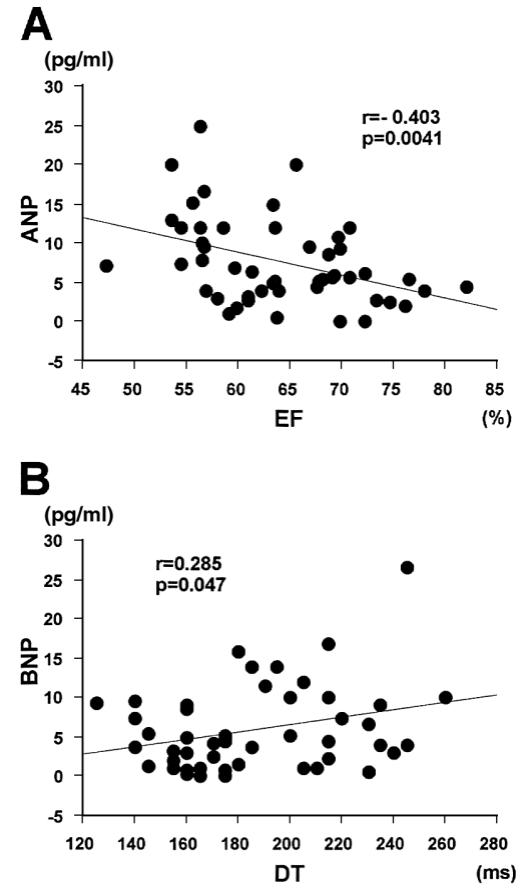

Fig 2. Correlation between atrial natriuretic peptide (ANP) and left ventricular ejection fraction (LVEF) (A) and between brain natriuretic peptide (BNP) and deceleration time of E wave (DT) (B) in all study participants. Plasma ANP concentrations negatively correlate with LVEF ( $r=-0.403, p=0.0041)(A)$ and plasma BNP concentrations positively correlate with DT $(\mathrm{r}=0.285, \mathrm{p}=0.047)(\mathrm{B})$.

linear regression analysis revealed that plasma BNP concentrations closely correlated with LV mass. The left ventricle is the predominant site of BNP synthesis in healthy men ${ }^{19,20}$ and the plasma concentration of BNP increases in response to various degrees of ventricular overload ${ }^{6-8}$ BNP is also secreted from the atria, but to a far lesser extent than from the ventricles, in patients with congestive heart failure ${ }^{6,19} \mathrm{We}$ also measured systolic wall stress at rest in the present study. However, because it was not elevated in either the judo or the marathon group compared with the control group, it was not a dependent variable that stimulated the release of natriuretic peptide. This is because systolic wall stress is most simply described by the following LaPlace relationship: $(\mathrm{P} \times \mathrm{R}) / 2 \mathrm{H}$, where $\mathrm{P}$ is systolic pressure, $\mathrm{R}$ is the radius of the $\mathrm{LV}$ and $\mathrm{H}$ is the thickness of the LV wall, ${ }^{21}$ and it was normalized by the correspondingly augmented LV wall thickness in both types of athlete.

Unlike BNP, plasma ANP concentrations were high only in the marathon group and correlated with both LAD index and LVD index, suggesting that ANP is secreted from the dilated LA and/or LV. Although ANP is predominantly produced in and secreted from the atria 3,4 the ventricular ANP gene is expressed during LV hypertrophy 22 and heart failure ${ }^{23}$ suggesting that the ventricular myocardium produces and secretes ANP into the blood circulation. ANP is stored and released by a regulated pathway in the atrium whereas it is released from the ventricle by constitutive secretory pathways in a similar manner to BNP24 Indeed, Yasue et al have reported that ANP is secreted from the LV as well as from the LA in patients with dilated cardiomyopathy9, ${ }^{9}$ However, plasma ANP in patients with essential hypertension accompanied by LV hypertrophy could be 
released from the LA in association with increased atrial work or atrial pressure rather than the hypertrophied LV per se, because LV compliance decreases in such patients ${ }^{26}$ Furthermore, Roman et al suggested that the major source of ANP secretion is not the volume-overloaded or hypertrophied LV, but the enlarged LA in valvular heart disease ${ }^{27}$ The right atrium may also contribute to the increased plasma ANP concentrations in the volume-overloaded heart. The present study also revealed that the LAD index was a significant determinant, suggesting that the LA is the predominant site of ANP secretion in the heart of dynamic athletes. We speculate that LA distension could be a more potent stimulus to ANP release than LV enlargement or hypertrophy in the presence of LV volume overload. Age significantly and independently contributed to the stepwise multivariate regression analyses for plasma concentrations of both ANP and BNP, which was consistent with previous reports showing a positive correlation between age and either ANP or BNP in healthy individuals $^{28}$ and in patients with heart disease ${ }^{29}$

LV systolic and diastolic functions were within the normal ranges in both static and dynamic athletes in the present study. Additionally, correlations between the increase in ANP and the decrease in LV systolic function, and between the increase in BNP and the decrease in LV diastolic function were significant. The findings in patients with hematological malignancies treated with cardiotoxic chemotherapeutic agents are similar insofar as increased ANP concentrations reflect systolic dysfunction ${ }^{30}$ whereas increased BNP concentrations reflect diastolic dysfunction. ${ }^{31}$ Hence, natriuretic peptides in athletes may also, at least in part, affect ventricular function. However, because the magnitude of the increase in natriuretic peptides in these athletes remained within much lower concentrations than those associated with pathological states, the physiological role(s) of elevated plasma concentrations of ANP and BNP in athletes remains unclear.

LV hypertrophy results from an adaptation to cardiac overload! $!^{3}$ The athlete's heart is also a result of functional and morphological adaptations to repeated exercise ${ }^{32}$ The present study found that plasma concentrations of natriuretic peptide in 2 types of athletes differed according to the type of cardiac hypertrophy.

\section{Acknowledgments}

This study was supported in part by Grants-in-Aid for Scientific Research on Priority Areas and for the 21st Century COE program (Life Science) from MEXT, Japan.

\section{References}

1. Raskoff WJ, Goldman S, Cohn K. The 'athletic heart': Prevalence and physiologyical significance of left ventricular enlargement in distance runner. JAMA 1976; 236: 158-162.

2. Mitchell JH, Haskell W, Raven PB. Classification of sports. J Am Coll Cardiol 1994; 24: 864-866.

3. Kangawa K, Matsuo H. Purification and complete amino acid sequence of a-human atrial natriuretic polypeptide. Biochem Biophys Res Commun 1984; 118: 131-139.

4. de Bold AJ. Atrial natriuretic factor: A hormone produced by the heart. Science 1985; 230: 767-770.

5. Sudoh T, Kangawa K, Minamino N, Matsuo H. A new natriuretic peptide in porcine brain. Nature 1988; 332: 78-81.

6. Yoshimura M, Yasue H, Okumura K Ogawa H, Jougasaki M, Mukoyama $\mathrm{M}$, et al. Different secretion pattern of atrial natriuretic peptide and brain natriuretic peptide in patients with congestive heart failure. Circulation 1993; 87: 464-469.

7. Nishikimi T, Yoshihara F, Morimoto A, Ishikawa K, Ishimitsu T, Saito Y, et al. Relationship between left ventricular geometry and natriuretic peptide levels in essential hypertension. Hypertension 1996; 28: $22-30$

8. Hasegawa K, Fujiura H, Doyama K, Miyamae M, Fujiwara T, Suga $\mathrm{S}$, et al. Ventricular expression of brain natriuretic peptide in hypertrophic cardiomyopathy. Circulation 1993; 88: 373-380.

9. Yasue H, Obata K, Okumura K, Kurose M, Ogawa H, Matsuyama K, et al. Increased secretion of atrial natriuretic polypeptide from the left ventricle in patients with dilated cardiomyopathy. J Clin Invest 1989; 83: 46-51.

10. Ogawa K, Oida A, Sugimura H, Kaneko N, Nogi N, Hasumi M, et al Clinical significance of blood brain natriuretic peptide level measurement in the detection of heart disease in untreated outpatients: Comparison of electrocardiography, chest radiography and echocardiography. Circ J 2002; 66: 122-126.

11. Imamura Y, Fukuyama T, Mochizuki T, Miyagawa M, Watanabe K. Prognostic value of iodine-123-metaiodobenzylguanidine imaging and cardiac natriuretic peptide levels in patients with left ventricular dysfunction resulting from cardiomyopathy. Jpn Circ J 2001; 65: $155-160$.

12. Matsui T, Tsutamoto T, Maeda K, Kusukawa J, Kinoshita M. Prognostic value of repeated ${ }^{123}$ I-metaiodobenzylguanidine imaging in patients with dilated cardiomyopathy with congestive heart failure before and after optimized treatments: Comparison with neurohumoral factors. Circ J 2002; 66: 537-543.

13. ACC/AHA guideline for the clinical application of echocardiography: Executive summary. A report of the American College of Cardiology/American Heart Association Task force on practice guidelines (Committee on Clinical Application of Echocardiography). $J$ Am Coll Cardiol 1997; 29: 862-879.

14. Devereux RB, Reichek N. Echocardiographic determination of left ventricular mass in man. Circulation 1977; 55: 613-618.

15. Schiller NB, Shah PM, Crawford M, DeMaria A, Devereux R, Feigenbaum H, et al. Recommendations for quantitation of the left ventricle by two-dimensional echocardiography: American Society of Echocardiography Committee on Standards, Subcommittee on Quantitation of Two-Dimensional Echocardiograms. J Am Soc Echocardiogr 1989; 2: 358-367.

16. Grossman W, Jones D, McLaurin LP. Wall stress and patterns of hypertrophy in the human left ventricle. J Clin Invest 1975; 56: $56-$ 64.

17. Hama N, Nakao K, Mukoyama M, Suga S, Ogawa Y, Kawabata Y, et al. Fundamental and clinical evaluation of 'Shionoria ANP', human atrial natriuretic peptide IRMA kit. Clin Report 1991; 25: $455-462$.

18. Yasue H, Yoshimura M, Jougasaki M, Itoh H, Suga S, Ogawa Y, et al. Plasma levels of brain natriuretic peptide in normal subjects and patients with chronic heart failure; measurement by immunoradiometric assay (IRMA). Horm Clin 1993; 41: 397-403.

19. Mukoyama M, Nakao K, Hosoda S, Suga S, Saito Y, Ogawa Y, et al. Brain natriuretic peptide (BNP) as a novel cardiac hormone in humans: Evidence for an exquisite dual natriuretic peptide system, ANP and BNP. J Clin Invest 1991; 87: 1402-1412.

20. Hosoda K, Nakao K, Mukoyama M, Saito Y, Jougasaki M, Shirakami G, et al. Expression of brain natriuretic peptide gene in human heart. Production in the ventricle. Hypertension 1991; 17: $1152-$ 1155.

21. Imamura T, McDermott P, Kent R, Nagatsu M, Cooper G IV, Carabello BA. Acute changes in myosin heavy chain synthesis rate in pressure versus volume overload. Circ Res 1994; 75: 418-425.

22. Nakagawa O, Ogawa Y, Itoh H, Suga S, Komatsu Y, Kishimoto I, et al. Rapid transcriptional activation and early mRNA turnover of brain natriuretic peptide in cardiocyte hypertrophy: Evidence for brain natriuretic peptide as an 'emergency' cardiac hormone against ventricular overload. J Clin Invest 1995; 96: 1280-1287.

23. Saito Y, Nakao K, Arai H, Nishimura K, Okumura K, Obata K, et al. Augmented expression of atrial natriuretic polypeptide gene in ventricle of human failing heart. J Clin invest 1989; 83: 298-305.

24. Bloch KD, Seidman JG, Naftilan JD, Fallon JT, Seidman CE. Neonatal atria and ventricles secrete atrial natriuretic factor via tissue-specific secretory pathway. Cell 1986; 47: 695-702.

25. Yasue H, Yoshimura M, Sumida H, Kikuta K, Kugiyama K, Jougasaki M, et al. Localization and mechanism of secretion of B-type natriuretic peptide in comparison with those of A-type natriuretic peptide in normal subjents and patients with heart failure. Circulation 1994; 90: 195-203.

26. Fouad FM, Slominski JM, Tarazi RC. Left ventricular diastolic function in hypertension: Relation to left ventricular mass and systolic function. J Am Coll Cardiol 1984; 3: 1500-1506.

27. Roman MJ, Devereux RB, Atlas SA, Pini R, Ganau A, Hochreiter C, et al. Relationship of atrial natriuretic factor to left ventricular 
volume and mass. Am Heart J 1989; 118: 1236-1242.

28. Clerico A, Del Ry S, Maffei S, Prontera C, Emdin M, Giannessi D. The circulating levels of cardiac neatriuretic hormones in healthy adults: Effects of age and sex. Clin Chem Lab Med 2002; 40: 371377.

29. Hirata Y, Matsumoto A, Aoyagi T, Yamaoki K, Komuro I, Suzuki T, et al. Measurement of plasma brain natriuretic peptide level as a guide for cardiac overload. Cardiovasc Res 2001; 51: 585-591.

30. Nousiainen T, Jantunen E, Vanninen E, Remes J, Vuolteenaho O,
Hartikainen J. Natriuretic peptides as markers of cardiaotoxicity during doxorubicin treatment for non-Hogkin's lymphoma. Eur $J$ Haematol 1999; 62: 135-141.

31. Suzuki T, Hayashi D, Yamazaki T, Mizuno T, Kanda Y, Komuro I, et al. Elevated B-type natriuretic peptide levels after anthracycline administration. Am Heart J 1998; 136: 362-363.

32. Huston TP, Puffer JC, Rodney WM. The athletic heart syndrome. $N$ Engl J Med 1985; 313: 24-32. 